\title{
Effect of remifentanil on intraoperative fluid balance: a retrospective statistical examination of factors contributing to fluid balance
}

\author{
Sayaka Ohara, Akiko Nishimura, Satoshi Tachikawa, Takehiko lijima \\ Department of Perioperative Medicine, Division of Anesthesiology, School of Dentistry, Showa University, Ohta City, Tokyo, Japan
}

\begin{abstract}
Background: Postoperative fluid retention is a factor that causes delay in recovery and unexpected adverse events. It is important to prevent intraoperative fluid retention, which is putatively caused by intraoperative release of stress hormones, such as $\mathrm{ADH}$ (anti-diuretic hormone) or others. We hypothesized that intraoperative analgesia may prevent pathological fluid retention. We retrospectively explored the relationship between analgesics and in-out balance in surgical patients from anesthesia records.

Methods: Anesthetic records of 80 patients who had undergone orthognathic surgery were checked in this study. Patients were anesthetized with either TIVA (propofol and remifentanil) or inhalational anesthesia (sevoflurane and remifentanil). During surgery, acetated Ringer's solution was infused for maintenance at a rate of $3-5 \mathrm{ml} / \mathrm{kg} / \mathrm{h}$ at the discretion of the anesthetist. The perioperative parameters, including the amount of crystalloid and colloid infused, and the amount of urine and bleeding were checked. Furthermore, we checked the amount and administration rate of remifentanil during the surgical procedure. The correlation coefficient between the remifentanil dose and the in-out balance or the urinary output was analyzed using the Pearson correlation coefficient. The contributing factor to fluid retention, including urinary output, was statistically examined by means of multivariate logistic regression analysis.

Results: A significant positive correlation was found between remifentanil dose and urinary output. Urinary output less than $0.04 \mathrm{ml} / \mathrm{kg} / \mathrm{min}$ was suggested to cause positive fluid balance. Although in-out balance approaches zero balance with increase in remifentanil administration rate, no contributing factor for near-zero fluid balance was statistically picked up. The remifentanil administration rate was statistically picked up as the significant factor for higher urinary output $(>0.04 \mathrm{ml} / \mathrm{kg} / \mathrm{min})\left(\mathrm{OR}, 2,644 ; 95 \% \mathrm{CI}, 3.2-2.2 \times 10^{6}\right)$ among perioperative parameters.

Conclusions: In conclusion, remifentanil contributes in maintaining the urinary output during general anesthesia. Although further prospective study is needed to confirm this hypothesis, it was suggested that fluid retention could be avoided through suppressing intraoperative stress response by means of appropriate maintenance of remifentanil infusion rate.
\end{abstract}

Keywords: Crystalloid Solutions; Fluid Balance; Fluid Therapy; Remifentanil; Urinary Output.

This is an Open Access article distributed under the terms of the Creative Commons Attribution Non-Commercial License (http://creativecommons.org/licenses/by-nc/4.0/) which permits unrestricted non-commercial use, distribution, and reproduction in any medium, provided the original work is properly cited.

\section{INTRODUCTION}

During general anesthesia, fluid balance should be monitored and maintained at an optimal level. General anesthesia itself causes fluid retention, as compared with the awake state [1]. This effect might be attributable to the stress response, which triggers the release of anti-diuretic hormone $(\mathrm{ADH})$. If this stress response is prolonged, intraoperative fluid retention can become a

Received: March 11, 2020 • Revised: May 25, 2020 • Accepted: June 8, 2020

Corresponding Author: Takehiko lijima, Department of Perioperative Medicine, Division of Anesthesiology, School of Dentistry, Showa University, Kitasenzoku 2-1-1 Ohta City, Tokyo 145-8515, Japan

Tel: +81-3-3787-1151 Fax: +81-3-3787-0248 E-mail: iijima@dent.showa-u.ac.jp

Copyright(C) 2020 Journal of Dental Anesthesia and Pain Medicine 
key factor in postoperative adverse events [2,3]. Avoiding fluid retention during the perioperative period can lead to a good prognosis. Over the last few decades, excessive fluid administration has been avoided, and the optimization of fluid therapy has been explored [4]. Even though fluids can be massively administered incidentally, adverse effects can be avoided if the fluid is rapidly excreted via the kidneys. The in-out balance may be more important than the amount of infused fluid in terms of avoiding postoperative adverse events [5]. The optimal in-out fluid balance to avoid adverse events has been explored clinically [6,7].

Painful stimuli are major factors for releasing $\mathrm{ADH}$, leading to fluid retention. The continuous infusion of remifentanil can maintain the level of analgesia, enabling a stress-less intraoperative condition. The continuous intraoperative infusion of remifentanil has been shown to enable insulin resistance to be avoided through a pathway involving the release of stress hormones [8]. Remifentanil was previously reported to increase urinary output by suppressing ADH release [9]. Therefore, sufficient analgesia through remifentanil infusion could conceivably be used to optimize the fluid balance. Here, we examined the effect of intraoperative remifentanil dose on the intraoperative fluid balance and retrospectively examined whether the in-out balance could be driven by the intraoperative use of remifentanil.

\section{METHODS}

\section{Retrospective examination of anesthetic records}

The anesthesia records of consecutive patients $(n=80)$ who underwent orthognathic surgery to correct deformities of the maxilla and mandible between 2016 and 2017 were retrospectively reviewed. No abnormal outcomes occurred among these consecutive patients; thus, none of the patients were excluded from the statistical analysis. Patients were anesthetized with either TIVA (propofol and remifentanil) or inhalational anesthesia (sevoflurane and remifentanil). After endo- tracheal intubation and monitor set-up, an arterial line was placed in a radial artery. During surgery, acetated Ringer's solution was infused for maintenance at a rate of 3-5 ml/ $/ \mathrm{kg} / \mathrm{h}$ and was administered on a supplementary basis as needed at the discretion of the anesthetist. We did not induce hypotension for down fracture of the maxilla. The bleeding amount was calculated using the weight of the gauze and a measured suction container, from which surgical irrigation fluid was subtracted. Information on the following perioperative parameters were obtained from the anesthetic records: age, height, weight, sex, surgical duration, duration of anesthesia, doses of remifentanil and fentanyl, and ASA classification.

To calculate the in-out balance, we calculated the amounts of fluid, crystalloid and colloid, that were administered subtracted by the urine output and the amount of bleeding. Since the amount of bleeding and the amount of administered colloid were similar and none of the cases required a transfusion, we did not differentiate the amounts of administered colloid and bleeding from the amount of administered crystalloid and the urine output.

\section{Statistical analysis}

The values were represented as the mean $+/-\mathrm{SD}$. The correlation coefficient between the remifentanil dose and the in-out balance or the urinary output was computed using the Pearson correlation coefficient (statistical software, SPSS ver.17; SPSS Inc.).

We calculated the propensity score using the original dataset that was divided according to the dose of remifentanil to reduce any bias between the two groups. The final dataset was used for data presentation and logistic regression analysis $(n=33$, each).

Perioperative variables, including the patients' background characteristics (age, weight, height, remifentanil administration rate $\mu \mathrm{g} / \mathrm{kg} / \mathrm{min}$, amount of bleeding, duration of anesthesia, surgical duration, systolic and diastolic blood pressure, and heart rate at the beginning and end of anesthesia), were entered in a multivariate logistic regression analysis (forward selection, maximum likelihood ratio method). The factors 
Table 1. Patient background characteristics after propensity score matching

\begin{tabular}{cc}
\hline Variable & Value \\
\hline Sex, M/F & $24 / 42$ \\
Age, years & $25 \pm 7$ (17-50) \\
Body height, cm & $164 \pm 7$ (150-185) \\
Body weight, kg & $58 \pm 10$ (35-101) \\
Anesthesia method & TIVA, 53/AOS, 13 \\
\hline
\end{tabular}

TIVA, total intravenous anesthesia; AOS, air-oxygen-sevoflurane anesthesia (max-min)

contributing to urinary outflow were then statistically extracted $(\mathrm{P}<0.05)$.

Since we were unable to find a study on how to calculate the appropriate sample size for this study, we performed a "post-hoc power analysis." Our sample size for the primary endpoint (urinary output less than 0.04 $\mathrm{ml} / \mathrm{kg} / \mathrm{min}$ ) was confirmed to be appropriate using the G-Power 3.1.9.4 statistical package. Specifically, $\alpha$ was set at .05 for the rejection of the null hypothesis, and the incident rate of a low urinary output (less than 0.04 $\mathrm{ml} / \mathrm{kg} / \mathrm{min})$ was 0.379 . The statistical power level $(1-\beta$ err prob) was calculated to be 0.811 , which was more than 0.8 .

\section{Ethical considerations}

This retrospective study was approved by the Clinical Research Ethics Committee of the Showa University School of Dentistry (DH2018-007;) and was registered at UMIN-CTR (UMIN000036073). The ethics committee approved the study on September 21, 2018. This study was disclosed on the department's homepage, and all the participants had an opportunity to request the exclusion of their medical records from this study.

\section{RESULTS}

The enrolled patients $(n=33)$ were relatively young and healthy (Table 1). All the patients underwent uneventful orthognathic surgical procedures that were completed under general anesthesia. The duration of anesthesia was $343 \pm 93 \mathrm{~min}$, the amount of bleeding

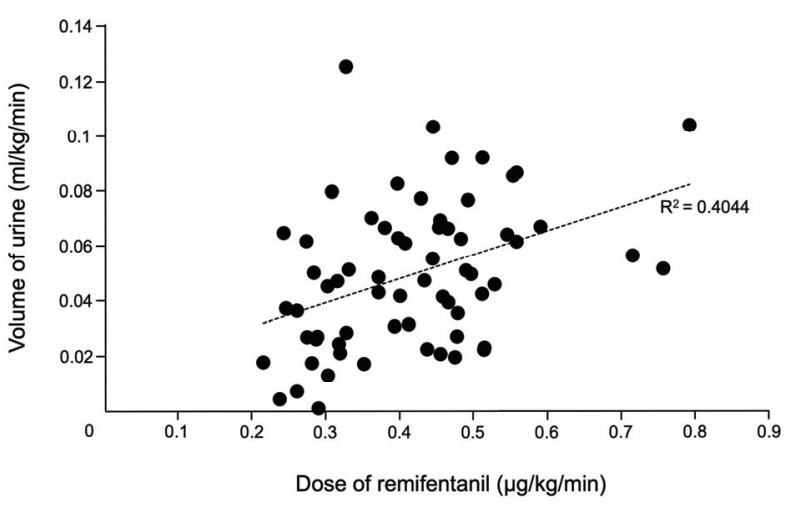

Fig. 1. Correlation between the infusion rate of remifentanil and urine output. The correlation was weak, although a statistical significance was confirmed between the two parameters.

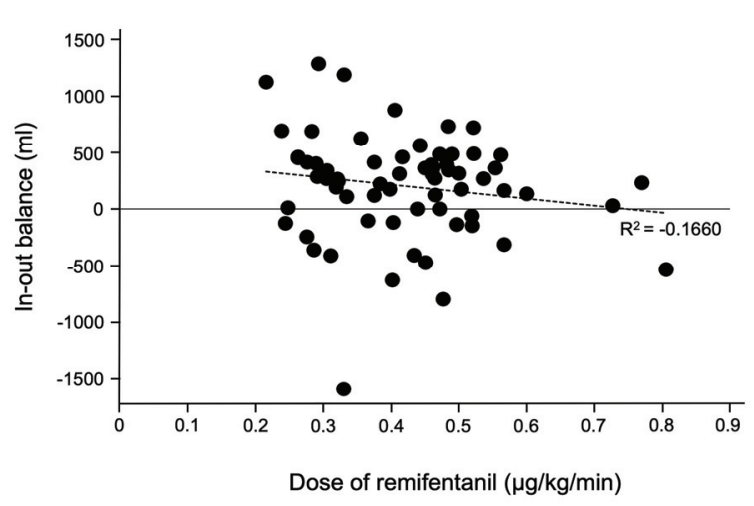

Fig. 2. Correlation between the infusion rate of remifentanil and fluid balance. Note that the fluid balance approached zero as the remifentanil dose increased.

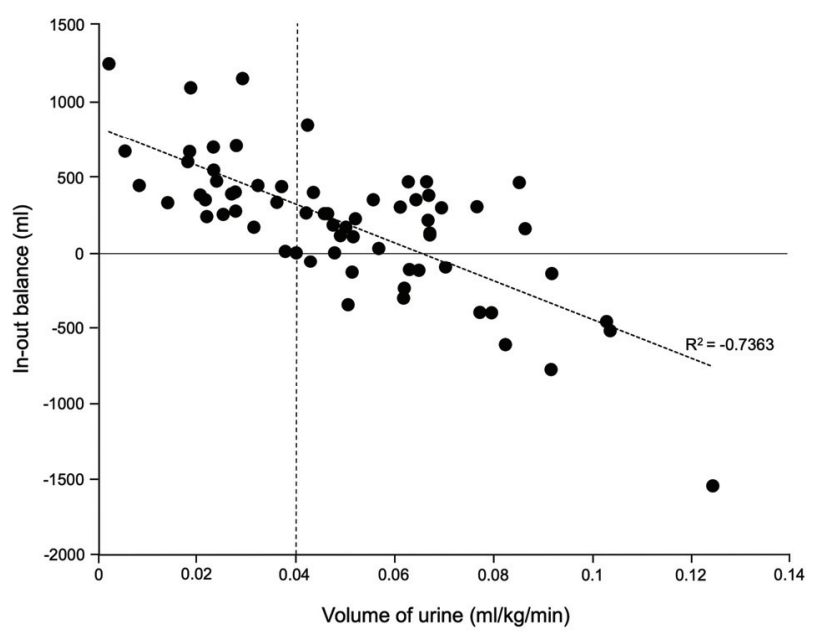

Fig. 3. Correlation between the urinary output rate and fluid balance. A strong negative correlation was found between the two parameters. We used $0.04 \mathrm{ml} / \mathrm{kg} / \mathrm{min}$ as a threshold to distinguish a positive and negative fluid balance.

was $223 \pm 153 \mathrm{ml}$, and the amount of crystalloid infusion 
Table 2. Bivariate analysis of factors associated with remifentanil administration rate

\begin{tabular}{lcc}
\hline & $\begin{array}{c}\text { Low dose of remifentanil } \\
<0.42 \mu \mathrm{g} / \mathrm{kg} / \mathrm{min}\end{array}$ & $\begin{array}{c}\text { High dose of remifentanil } \\
>0.42 \mu \mathrm{g} / \mathrm{kg} / \mathrm{min}\end{array}$ \\
\hline Number of patients & 33 & 33 \\
Age, years & $24.4 \pm 6.2$ & $165.1 \pm 7.6 \pm 6.4$ \\
Body height, cm & $165.3 \pm 8.0$ & $57.5 \pm 9.4$ \\
Body weight, $\mathrm{kg}$ & $57.7 \pm 10.4$ & $240 \pm 159$ \\
Blood loss, ml & $207 \pm 147$ & $1,165 \pm 559^{*}$ \\
Urine volume, ml & $826 \pm 600$ & $3.2 \pm 1.2^{*}$ \\
Urine ate, ml/min & $2.4 \pm 1.5$ & $1,561 \pm 524^{*}$ \\
Infusion volume, ml & $1,269 \pm 468$ & $1,309 \pm 389$ \\
Crystalloid volume, ml/min & $1,125 \pm 406$ & $156 \pm 352$ \\
Fluid balance, ml & $236 \pm 532$ & $0.56 \pm 1.16$ \\
Fluid balance, ml/min & $0.73 \pm 1.49$ & $293 \pm 87$ \\
Duration of surgery, min & $279 \pm 87$ & $128 \pm 19$ \\
Pre Sys BP & $124 \pm 12$ & $77 \pm 12$ \\
Pre Dia BP & $71 \pm 8$ & $82 \pm 18$ \\
Pre HR & $76 \pm 14$ & $119 \pm 17$ \\
Post Sys BP & $120 \pm 16$ & $71 \pm 11$ \\
Post Dia BP & $67 \pm 11$ & $87 \pm 22$ \\
Post HR & $85 \pm 18$ & 27 \\
\hline
\end{tabular}

${ }^{*} \mathrm{P}<0.05$

Pre, the value at the induction of anesthesia; Post, the value at the end of anesthesia; Sys, systolic; Dia, diastolic; BP, blood pressure; HR, heart rate

Table 3. Multivariate logistic regression analysis of predictors associated with urinary outflow

\begin{tabular}{lccc}
\hline & Odds ratio & $95 \% \mathrm{Cl}$ & $\mathrm{P}$ \\
\hline Remifentanil dose, $\mu \mathrm{g} / \mathrm{kg} / \mathrm{min}$ & 2,644 & $3.2-2,203,999$ & 0.022 \\
Body weight, $\mathrm{kg}$ & 0.912 & $0.845-0.984$ & 0.017 \\
Infusion volume, $\mathrm{ml}$ & 1.002 & $1.001-1.004$ & 0.005 \\
\hline
\end{tabular}

95\% Cl, 95\% confidence interval

was $1217 \pm 405 \mathrm{ml}(\max , 2500 \mathrm{ml}$; min, $500 \mathrm{ml})$. None of the patients required a transfusion.

We confirmed a significant correlation $(\mathrm{r}=0.366 \mathrm{P}$ $<0.01$ ) between the urinary output rate and the remifentanil infusion rate (Fig. 1). The remifentanil infusion rate was the averaged value of the remifentanil infusion rate during anesthesia. Furthermore, we presented the relationships between the remifentanil infusion rate and the intraoperative fluid balance (Fig. 2). Of note, the fluid balance approached zero as the remifentanil dose increased.

However, we failed to find a factor among the perioperative parameters that contributed to a low fluid balance (near-zero, less than $\pm 500 \mathrm{ml}$ ) using logistic regression analysis. As noted in Fig. 2, the remifentanil dose was not a dependent parameter for fluid balance.
The urinary output rate showed a linear relationship with the fluid balance, and a value of $0.04 \mathrm{ml} / \mathrm{kg} / \mathrm{min}$ was thought to be the threshold for a positive and negative fluid balance (Fig. 3). This binary can be used as an indirect parameter for fluid balance. We used this value as a binary to examine factors among the perioperative parameters that contributed to the urinary output rate statistically. We stratified the patients into two groups according to the remifentanil administration rate: a higher group (more than $0.42 \mu \mathrm{g} / \mathrm{kg} / \mathrm{min}, \mathrm{n}=33$ ) and a lower group (less than $0.42 \mu \mathrm{g} / \mathrm{kg} / \mathrm{min}, \mathrm{n}=33$ ). We found statistically significant differences in each of the parameters between the two groups, except for body height (Table 2).

mos The logistic regression analysis showed that the average speed of remifentanil administration rate 
$(\mu \mathrm{g} / \mathrm{kg} / \mathrm{min})$ was the $\mathrm{t}$ significant factor contributing to a high urinary output $(>0.04 \mathrm{ml} / \mathrm{kg} / \mathrm{min})(\mathrm{OR} ; 2,644$, $95 \%$ CI; $3.2-2.2 \times 10^{6}$ ) (Table 3). Body weight and infusion volume had small but significant effects on urinary output (Table 3).

\section{DISCUSSION}

Intraoperative fluid infusion is based on the traditional concept of compensating for an assumed fluid deficit. The estimated fluid deficit is predicted using a formula, including items such as the volume of the third space, insensible vapor from the surgical site, preoperative "not per-os" fluid, and other parameters. However, if the surgery is prolonged and more invasive, the accumulated fluid cannot be readily excreted, resulting in fluid retention $[3,10]$. Over the last decade, pathological fluid retention has become an issue of concern, and fluid therapy oriented toward the in-out balance has become a priority [7,11]. Therefore, our basic knowledge of intraoperative fluid balance should be expanded.

Several reports have demonstrated that the intraoperative use of remifentanil increases urinary output [9,12-15]. During cardiac surgery, renal blood flow can be temporarily disturbed because of fluctuating cardiac output. However, remifentanil has been shown to offer an advantage over fentanyl in terms of urinary output [15]. Furthermore, laparoscopic abdominal surgery also carries a risk of disturbances in renal blood flow because of unphysiological intraabdominal pressure. Even during this type of surgery, remifentanil has an advantage in terms of dose-dependent urinary output [13]. This observation was supported by another independent study measuring stress hormone levels during pneumoperitoneum under remifentanil administration [16]. Terashi reported that remifentanil temporarily improved the glomerular filtration rate during the postoperative period in patients with chronic kidney disease [17]. These clinical data suggest that remifentanil might have a direct effect on renal function. However, the most convincing mechanism would be a potent and stable analgesic effect of remifentanil on the hormonal control of urinary production. Shinoda et al. demonstrated that remifentanil contributed to an increase in urine production over fentanyl by nearly three times, and this increase was accompanied by a suppression of the release of stress hormones, $\mathrm{ADH}$, adrenaline, and others [9]. This hypothesis is supported by a report from another independent institute. Winterhalter compared the release of stress hormones in a remifentanil group and an intermittent fentanyl group among cardiac surgery cases [18]. A dose-response effect of remifentanil on $\mathrm{ADH}$ release was also demonstrated during pneumoperitoneum for laparoscopic colectomy [19]. Remifentanil administration before peritoneal incision has also been reported to have a partial effect on the reduction of hormonal stress response during cesarean sections [20]. Thus, the effect of remifentanil on urine output could be attributed to a hormonal pathway through an analgesic effect. Our data demonstrated that the in-out balance converged to zero, and not toward a negative balance, in parallel with the remifentanil dose. This result suggests that remifentanil prevents fluid retention, rather than facilitating urinary production. However, we failed to identify remifentanil administration rate as a significant factor influencing fluid balance. In this retrospective study, we were only able to obtain indirect evidence explaining the relationship between the analgesic effect and fluid balance. We found a significant correlation between the remifentanil dose and urinary output (Fig. 1). Furthermore, there was a significant correlation between urinary output rate and fluid balance. This strong correlation offered us a threshold value for a urinary output rate resulting in a positive fluid balance. Thus, we used a threshold of 0.04 $\mathrm{ml} / \mathrm{kg} / \mathrm{h}$ to identify perioperative parameters contributing to fluid retention, since a value less than $0.04 \mathrm{ml} / \mathrm{kg} / \mathrm{h}$ corresponded to a positive fluid balance (Fig. 3). This threshold corresponded to $2.4 \mathrm{mg} / \mathrm{kg} / \mathrm{h}$, which is considerably higher than the usual intraoperative urine production goal. However, this threshold was useful as a benchmark for estimating a positive fluid balance. Thus, 
we speculated that the remifentanil administration rate was a significant parameter for preventing fluid retention.

We previously demonstrated that fluid absorption, expressed as the retained fraction of the infused volume, does not depend on the infused fluid volume. In contrast, the filtrated volume, expressed as the excreted fraction of the infused volume, closely correlated with the infused volume [21]. Thus, fluid retention is probably affected mainly by hormonal control, rather than the infused volume.

Our study should be interpreted with caution. This study was a retrospective analysis of anesthesia records. A specific protocol for intraoperative fluid therapy was not used in this study. Thus, the decisions of individual anesthetists regarding fluid therapy may have influenced the study findings. However, a higher dose of remifentanil was shown to not induce fluid retention. A prospective study, including a control group, would be necessary for elucidating the etiological relationship between remifentanil and fluid balance. Furthermore, a hormonal analysis would also provide useful information for interpreting the results of this study.

All the study subjects were healthy, and none of them had pathological fluid retention postoperatively. This study cohort might not be suitable for detecting factors that lead to the deterioration in fluid retention. However, this uniform cohort was suitable for detecting factors that influenced urinary output, which was driven by multiple factors.

In conclusion, remifentanil increases the urinary output, thereby contributing to the optimization of postoperative fluid balance. Further prospective study may help to elucidate the relationship between intraoperative analgesia and fluid balance.

\section{AWHOR ORGIDS}

Sayaka Ohara: https://orcid.org/0000-0003-2691-9587

Akiko Nishimura: https://orcid.org/0000-0003-3670-9954

Satoshi Tachikawa: https://orcid.org/0000-0003-3662-9612

Takehiko lijima: https://orcid.org/0000-0001-5300-2796
AUWHOR CONIRBAUIIONS

Sayaka Ohara: Data curation, Formal analysis, Investigation, Methodology, Project administration, Writing - original draft, Writing - review \& editing

Akiko Nishimura: Formal analysis, Methodology, Writing - original draft

Satoshi Tachikawa: Data curation, Investigation

Takehiko lijima: Conceptualization, Data curation, Formal analysis, Methodology, Supervision, Writing - original draft, Writing - review \& editing

ACKNOWLEDGEMENTS: The authors would like to thank Ms. Myrna Harrod for her English language review. We declare no specific funding supporting this study, including any commercial, non-commercial, or any other association.

DECLARATION OF INTERESTS: The authors declare that they have no conflicts of interest.

FUNDING: This research is supported by the departmental fund only.

REGISTRATION AND ETHICAL APPROVAL: This retrospective study is registered in our hospital (DH2018-007;) at UMIN-CTR (official association for clinical trial registry) (UMIN000036073). The ethical committee approved this retrospective study; the registered number is "DH-2018-007."

INFORMED CONSENT: Informed consent was obtained in the form of opt-out on the website.

\section{REFERENCES}

1. Norberg A, Hahn RG, Li H, Olsson J, Prough DS, Borsheim E, et al.. Population volume kinetics predicts retention of $0.9 \%$ saline infused in awake and isofluraneanesthetized volunteers. Anesthesiology 2007; 107: 24-32.

2. Brandstrup B. Fluid therapy for the surgical patient. Best Pract Res Clin Anaesthesiol 2006; 20: 265-83.

3. Lobo DN, Bostock KA, Neal KR, Perkins AC, Rowlands BJ, Allison SP. Effect of salt and water balance on recovery of gastrointestinal function after elective colonic resection: 
a randomised controlled trial. Lancet 2002; 359: 1812-8.

4. Iijima T Brandstrup B, Rodhe P, Andrijauskas A, Svensen $\mathrm{CH}$. The maintenance and monitoring of perioperative blood volume. Perioper Med (Lond) 2013; 2: 9.

5. Brandstrup B. Finding the right balance. N Engl J Med 2018; 378: 2335-6.

6. Li C, Wang H, Liu N, Jia M, Zhang H, Xi X, et al. Beijing Acute Kidney Injury Trial W. Early negative fluid balance is associated with lower mortality after cardiovascular surgery. Perfusion 2018; 33: 630-7.

7. Wuethrich PY, Burkhard FC, Thalmann GN, Stueber F, Studer UE. Restrictive deferred hydration combined with preemptive norepinephrine infusion during radical cystectomy reduces postoperative complications and hospitalization time: a randomized clinical trial. Anesthesiology 2014; 120: 365-77.

8. Taniguchi H, Sasaki T, Fujita H, Takano O, Hayashi T, $\mathrm{Cho} \mathrm{H}$, et al. The effect of intraoperative use of high-dose remifentanil on postoperative insulin resistance and muscle protein catabolism: a randomized controlled study. Int J Med Sci 2013; 10: 1099-107.

9. Shinoda T, Murakami W, Takamichi Y, Iizuka H, Tanaka M, Kuwasako Y. Effect of remifentanil infusion rate on stress response in orthopedic surgery using a tourniquet application. BMC Anesthesiol 2013; 13: 14.

10. Brandstrup B, Tønnesen H, Beier-Holgersen R, Hjortso E, Ording H, Lindorff-Larsen $\mathrm{K}$, et al. Effects of intravenous fluid restriction on postoperative complications: comparison of two perioperative fluid regimens: a randomized assessor-blinded multicenter trial. Ann Surg 2003; 238: 641-8.

11. Brandstrup B, Svendsen PE, Rasmussen M, Belhage B, Rodt SA, Hansen B, et al. Which goal for fluid therapy during colorectal surgery is followed by the best outcome: near-maximal stroke volume or zero fluid balance? $\mathrm{Br} \mathrm{J}$ Anaesth 2012; 109: 191-9.

12. Kawai M, Nakata J, Kawaguchi M, Takahashi T, Hara $\mathrm{M}$, Yamaguchi S, et al. Comparison of urinary output during general anesthesia, between patients administered with remifentanil and those without remifentanil administration. Masui 2010; 59: 179-82.
13. Ishikawa K, Sakai A, Nagata H, Wakimoto M, Suzuki T, Oouchi S, et al. Remifentanil increases urine output in patients undergoing laparoscopic colectomy. Masui 2012; 61: $526-30$.

14. Yago Y, Tajiri O, Ito H, Kanazawa M, Tateda T. Effect of remifentanil on urine output during gynecological laparoscopic surgery. Masui 2009; 58: 613-5.

15. Myles PS, Hunt JO, Fletcher H, Watts J, Bain D, Silvers A, et al. Remifentanil, fentanyl, and cardiac surgery: a double-blinded, randomized, controlled trial of costs and outcomes. Anesth Analg 2002; 95: 805-12, table of contents.

16. Aceto P, Dello Russo C, Lai C, Perilli V, Fucci N, De Giovanni N, et al. Relationship between blood remifentanil concentration and stress hormone levels during pneumoperitoneum in patients undergoing laparoscopic cholecystectomy. Eur Rev Med Pharmacol Sci 2017; 21: 4419-22.

17. Terashi T, Takehara A, Kuniyoshi T, Matsunaga A, Kawasaki K, Kanmura Y. Remifentanil temporarily improves renal function in adult patients with chronic kidney disease undergoing orthopedic surgery. J Anesth 2013; 27: 340-5.

18. Winterhalter M, Brandl K, Rahe-Meyer N, Osthaus A, Hecker H, Hagl C, et al. Endocrine stress response and inflammatory activation during CABG surgery. A randomized trial comparing remifentanil infusion to intermittent fentanyl. Eur J Anaesthesiol 2008; 25: 326-35.

19. Watanabe K, Kashiwagi K, Kamiyama T, Yamamoto M, Fukunaga M, Inada E, et al. High-dose remifentanil suppresses stress response associated with pneumoperitoneum during laparoscopic colectomy. J Anesth 2014; 28: 334-40.

20. Draisci G, Valente A, Suppa E, Frassanito L, Pinto R, Meo F, et al. Remifentanil for cesarean section under general anesthesia: effects on maternal stress hormone secretion and neonatal well-being: a randomized trial. Int J Obstet Anesth 2008; 17: 130-6.

21. Nishimura A, Tabuchi Y, Kikuchi M, Masuda R, Goto $\mathrm{K}$, Iijima $\mathrm{T}$. The amount of fluid given during surgery that leaks into the interstitium correlates with infused fluid volume and varies widely between patients. Anesth Analg 2016; 123: 925-32. 